\title{
Two Forms of Responsibility - Organizational and Societal
}

\author{
Robert Albin ${ }^{1}$ iD \\ (C) Springer International Publishing AG 2017
}

\begin{abstract}
My aim in this article is twofold. First, I will illuminate the triangular conceptual connections between responsibility, authority, and power as they are exposed in the organizational realm; second, I will show how the three concepts are distinct. Relying on the work of Peter Strawson and his followers on responsibility for my point of departure, I will show that the connection between the inner corporational authority and its inner matching responsibility is different from the connection between the outer corporational forces and influences and the CSR that they develop in reaction to these. This will expose another important distinction between two kinds of responsibility: the organizational kind, as instantiated in organizations, and the social kind, which constitutes the outer aspect of the CSR. Though many thinkers address different kinds of responsibility, a comparative perspective of these different concepts is missing. I attempt to bring three of these separate discourses together to examine them alongside one another, evaluating them in the light of their differences and similarities. This will expose a new typology of 'responsibility' that penetrates and illuminates the relations between corporations and society and as such enhance our understanding of organizational responsibility.
\end{abstract}

Keywords Responsibility · Accountability · Power - Corporate social responsibility · Authority

\section{Introduction}

The conceptual connection between authority and responsibility is well known, theoretically as well as practically (Marmor 2011; Pink 2009). In the realm of organizational labour, it is widely accepted that there is no responsibility without authority. According to this view, authority is a necessary condition for bearing responsibility. Nevertheless, the conceptual connection seems to grow fainter when considering CSR, i.e. corporations' responsibility to society, since from a corporation's view society is mainly conceptualised in marketing terms as a vast reservoir of potential clients rather than organized civilians. Therefore, corporations do

Robert Albin

albin@sapir.ac.il

1 The Department of Liberal Arts, Sapir College, 79165 Hof-Ashkelon, Israel 
not tend to follow public orders or dicta. They rather represent a collective endeavour of their own - a profit-oriented one. This is not to suggest that corporations enjoy unlimited freedom. On the contrary. They are monitored and influenced by societal forces known as stakeholders (Detomasi 2008; Burchell and Cook 2013; Lee et al. 2013). My aim in this article is to illuminate the triangular conceptual connections between responsibility, authority, and power, and to distinguish between them. Relying on moral responsibility for my point of departure, I will show that the connection between the inner corporational authority and its inner matching responsibility is different from the connection between the outer corporational forces and influences and the CSR that they develop in reaction to these forces. This will expose another important distinction between two kinds of responsibility: the organizational kind, as instantiated in corporations, and the societal kind, which constitutes the outer aspect of the CSR. While thinkers of different philosophical schools draw on responsibility in respective separate veins of discourse, I bring, for the first time, three of those separate discourses together to examine them alongside one another, evaluating them in light of their differences and similarities. This exposes a new typology of 'responsibility'. It penetrates and illuminates the relations between corporations and society as well as enhancing our understanding of two forms of organizational responsibility.

My conceptual investigation originates from a wide scholarship on moral responsibility (Strawson 1993; Watson 2009; Shoemaker 2011; Macnamara 2011), which I apply to both forms of responsibility, which I flesh out henceforth: organizational as well as societal. To clarify, three conceptions of responsibility are presented here. The first is elaborated in detail by Peter Strawson and his followers, while the other two are presented in this article as two separate forms of organizational responsibility. Although some writers point out the differences between moral duties and other kinds of duties, a consensus on such a distinction has yet to be reached.

\section{Power}

Power and authority are not identical, though they are often considered to be the causes of actions for which an agent is responsible (Osorio-Kupferblum 2015). Sometimes a manager does not have the authority to direct such and such an operation, but nevertheless the employee obeys for the manager is charismatic and exercises an immense power of persuasion over the employee. Other managers may hold a great amount of formal authority and yet experience difficulties motivating their staff to work in accordance with their directives. In light of this, the distinction between authority and power may look a clear-cut distinction, but in fact the literature on the subject is divided. Some scholars support the distinction (Osorio-Kupferblum 2015; van Oosterhout 2007), while others seem to implicitly ignore it (Marmor 2011). Some, although they acknowledge it in theory, firmly discard 'authority' in any form, since it undermines their efforts to explain cooperative behaviour by the powers of the market alone (Alchian and Demsetz 1972). There are good arguments in favour of all mentioned approaches. Recognizing this, I propose absorbing the advantages of them all, thereby rejecting the distinction between power and authority as metaphysical but retaining it as a context sensitive one.

In what follows I will use 'power' and 'authority' in two distinctive ways: while the first is the public's (consumers and other agents in society) power to regulate corporations' actions, the second focuses on the inner institutional authority of corporations. This distinction is an 
addition to a well-known distinction between the political sphere and the market, which has already been acknowledged and discussed by many scholars (Anderson 1990; Scherer et al. 2014; Arenas et al. 2013; Habermas 1998). Nevertheless, the distinction between the political sphere and the market has not often been considered a categorical one. As a result, those spheres were not considered mutually exclusive and the possibility of mixing the political with the economic sphere seemed appealing as business ethics developed. Many felt that state regulation over business had weakened to a dangerous point that could result in economic and societal catastrophes. The 2008 subprime crisis in the US was one example of such a disaster. Hence the idea that businesses bear some social responsibilities became more and more plausible for scholars as it did for the general public. In light of these changing ideas, scholars became convinced of the need for corporate businesses to engage in the political sphere, to acknowledge their social responsibilities and to abide by them (Pies et al. 2014; Arenas et al. 2013; Siltoja and Onkila 2013).

In his influential 'theory of deliberative democracy' (1998), Habermas expresses his commitment to democracy and recognizes the need to reconcile it with the forces of the market, since in the modern era they have become alienated from each other to a dangerous extent. The rational discourse, one of the core values supporting the modern state, has become more and more biased towards pragmatic ends, according to Habermas. Scientific and economic practices are both examples of such ends, which eventually subdued non-partial, pure, and absolute uses of rationality that originally defined the common good of a community. According to Habermas, the modern state in the global era is a power-poor agent that has very little influence on the force of global corporations (Habermas 2001). Many corporations moved their production to third-world countries in order to cut salary expenses. Others implement international financial transactions, avoiding local obstacles raised by states. All of these changes resulted in an increase in social inequality, and exhausted the states' ability to contribute to the common good of its civilians. According to Habermas, the (democratic) state is responsible for the public's good, not corporations. But the market sphere has become dominant enough to impoverish the public sphere by virtue of introducing its logic, values, and discourse into the latter. Retaining a rational discourse, through which humans can understand their social condition and are able to choose between many courses of action and values, is crucial, according to Habermas. Such a discourse enables free citizens to construct, present, and dwell on arguments in a process of deliberation that takes place in the public sphere. Such rational discourse will be richer than all others and in particular will be non-biased. Such discourse is considered a tool of deliberation for use in our collective mode of life.

I suggest reading Habermas' theory of deliberative democracy as promoting the idea that one necessary condition for a firm's effectively integrating into the political and social spheres is its ability to contain social and political criticism and to react to it in a productive way. Reacting, of course, goes only half way in a firm's fulfilling its political role in society. The other half, i.e. the other necessary condition, is for the firm to be able to initiate action in the public sphere with other agents and to be able to communicate effectively with them (Habermas 1998). In recent years business corporations have faced increasing public interventions in their conduct so as to modify them and bring them as close as possible to a higher ethical standard. Following major crises or scandals that are thought to be the result of corporations' conduct, the public exercises its political power in order to regulate and influence corporations in the market. Thus, political power and social pressure are wielded on business corporations in reaction to corporate violation of the public interest. These powers regard environmental issues (Pellizzoni 1999), as well as in employees' rights ( $\mathrm{Xu}$ and $\mathrm{Li}$ 2012), the 
food and drug industries and their relation to food safety (Lee et al. 2013), issues of obesity, especially regarding the way the fashion industry influences young girls' attitudes toward their bodies, and many more (Schrempf 2014; Burchell and Cook 2013).

One of the prominent fruits of 'the deliberative theory' is related to the development of CSR as an academic and theoretical endeavour. Nonetheless, CSR is more than this: it is a political, social, and business instrument for encouraging each of these agents to strive and achieve their mutually coordinated goals and implement their values (Scherer and Palazzo 2004). The latter view presents a new perception of CSR that rejects the notion that relations between businesses and society are constituted upon mere power. Once the dominance of power is reduced in business-society discourse, it allows other deliberative components to take place. Consequently, a much more substantive place is being given to deliberation between parties, instead of them forcing each other into a corner. This is a process of investigating the common grounds, listening and learning about each other, negotiating, and bargaining. It is open to criticism, but at the same time it is not to be concluded unilaterally by one side alone. This perception of the discourse rests mainly on a pragmatic point of view that does not reject facts, but rather prefers them over an abstract theory of human values. It means, on the one hand, that its followers acknowledge that a societal mode of existence cannot be strictly governed according to political and moral abstract ideologies. Furthermore, followers of this view find evidence for their anti-theoretical approach in a variety of examples of business corporations increasingly engaging in promoting and supporting communal needs at their own expense. On the other hand, they do not all together exclude the validity of moral norms and responsibilities. This double grip on the political role of CSR involves an ideological normative zeal alongside the pragmatic one. After all, identifying that CSR has a political role is in itself a value-driven project.

On a descriptive level, the political role of CSR presents a somewhat ambiguous picture. Though power no longer plays the leading role in the business-society equation, it is still there as an important component. At times it is reduced to a lesser position, while at other times it plays a more central role. Public power was exercised against Nike's sweatshops in the 1990s (Dreier 1999), while a more refined kind of communication was applied so as to produce a new, interesting and surprising alliance between the Italian energy giant Enel and Greenpeace in their joint battle for the development of low-carbon technologies (Carrington 2015). Nevertheless, the formation of such surprising coalitions between parties is not to be understood in distinction from the intense and long history of strife between them. It is rather one outcome of a bitter war. Political CSR in such a case is devoted to deliberation as a means of promoting mutual interests rather than exercising brute political power. Such present relations between the parties seem to be an ideal type of deliberative democracy. Nevertheless, the way each party is to respond to the other remains to be determined in what follows.

\section{Power and Responsibility}

\section{Moral Responsibility}

'Responsibility' seems to be one of the richest concepts in the modern ethical vocabulary, as its widespread use suggests. It is embedded in our moral and ethical language. As a relatively new addition to our moral and ethical practices, 'responsibility' allows us to talk of our moral and ethical duties in a new way; it implicitly interrelates our deontological vocabulary with virtueethical ideas. Responsibility is a complex, normative notion used in a wide range of different 
contexts and hence with a level of ambiguity. A short clarification will thus be helpful. Many of the contributions on responsibility are influenced by the seminal work of Peter Strawson, who coined some constitutive expressions on the subject (Strawson 1993). Strawson portrayed the responsibility for one's conduct in terms of human reactions to his or her conduct 'reactive attitudes'. These attitudes can be either positive or negative. Through reactive attitudes we present our indignation, resentment, as well as approval, disapproval, admiration, forgiveness, gratitude, sympathy, and the like, to others' conduct. Reacting to others' conduct in such ways exposes that and how we hold them responsible for their actions. Following this, Gary Watson presents two faces of moral responsibility: responsibility as deep moral appraisal and accountability (Watson 2009). Accordingly, responsibility as deep moral appraisal is a virtue-ethical mode of evaluating a person's moral capacities and character as they are embodied in his or her conduct. Such appraisal is undertaken in terms of praise and blame and in light of certain sets of standards and maxims. Accountability is something else. Imagine that a colleague of mine with whom I have started to write a paper abruptly quits and refuses to participate in our mutual project, without giving me a reason. In such a case, she is accountable to me for breaking her promise and for my consumed time. Being accountable here means she deserves a 'negative attitude' on my part, not only expressing some blame. I may rebuke her in order to make her acknowledge her fault. I may even avoid her company for some time.

Understanding accountability in such a manner implies its deontic nature. Coleen Macnamara pulls this thread explicitly. According to her view, holding my colleague accountable for breaking her promise to me and for my wasted time is entailed by my colleague's violation of norms through which personal relations are managed. Holding her accountable is in accordance with some 'ought' that renders its deontic nature (Macnamara 2011). I will return to the deontic nature of accountability later.

However, my account of responsibility takes a different and a more concrete perspective, as I focus on another form of responsibility - an institutional form of responsibility. Moreover, I concentrate on accountability, as it appears to be of more use in revealing the secrets of institutional relations. Yet my account is aligned - due to its terminological proximity - with Strawson's and his followers work. Following Watson and Macnamara, concerning the distinction between responsibility (as deep moral appraisal, as Watson calls it) and accountability, I find Shoemaker's third component of responsibility - namely, answerability - vital for an understanding of responsibility (Shoemaker 2011). While generally in accordance with Macnamara and Watson regarding accountability as related to all kinds of sanctions, Shoemaker considers answerability to be associated with the charge to justify one's actions. This is done by conveying reasons for acting in such and such a way. If I fail to appear at the appointed time to one of my weekly meetings with my teenage daughter, I should answer for this, and if my answer is rejected as unsatisfactory I will be accountable for missing the appointment with her. I might say that I was caught in a horrible traffic jam on my way to see her, and this would be considered my reason for missing the meeting. It is important to note that not every explanation qualifies as an answer, as an action or an omission requires a moral explanation which would work as a moral justification that transcends causal explanation. If I answer my daughter that the reason that I am late is that my car drove slowly, this will not qualify as a moral reason for my delay. My explanation should state my value, in this case the importance I attribute to meeting her, and then mention the traffic jam that prevented the meeting. Thus, being answerable-responsible means that one bears a burden, an ought that projects beyond mere causal explanation as a moral explanation that points at the values attributed to one. Note that for Shoemaker answerability as a responsibility-component is case 
sensitive. He mentions some instances of responsibility in which answerability is not required. One of these examples is found in attitudes based on emotional commitments, such as the attitude of parental care for children regardless of the child's behaviour:

After my child has become a serial killer, for instance, I may arrive at the consciously held propositional belief that he's a worthless human being, that he's dead to me. And yet when I read of his upcoming execution, I may well up with tears or fall into a depression. "I still care about him," I may say. "There are no reasons to do so- he's an awful man — but it still matters to me what happens to him. (Shoemaker 2011, 610)

\section{Organizational Responsibility}

On the level of task-oriented practice, which is the bread and butter of the organizational realm, responsibility is considered through somewhat different notions, according to which it is a combination of three things: imputability, liability, and accountability (Robinson 2009; McKenny 2005). Imputability means that there is a specific party, an individual or a collective agent, that is responsible for a specific duty. Liability relates to a specific responsibility for something the agent has to fulfil, and accountability is related to the party to which the agent is responsible. Of these three components, accountability is most relevant to the relationships between parties. Though these notions are used unevenly and hence to a certain extent obscure, Macnamara's interpretation of accountability is perfected to fit the institutional reality. Accountability, according to her, works in both directions of the time line, backward as well as forward: "Holding another accountable, then, has both a backward- and a forward-looking leg. The backward-looking leg is the leg of punishments and reproofs; the forward-looking, the leg of holding demands" $(2011,92)$. The inner institutional realm is made up of hierarchies which divide the managers that issue directives and the subjects who fulfil them. Those relations are an essential part of all organizations, and exploring them can enrich our understanding of how responsibility within them manifests.

Accountability operates as a distinct aspect of responsibility, and if Shoemaker is right to add answerability to the moral discussion, here in the realm of institutions, answerability fits to an even greater extent, as I further show. There is a difference between the two realms, the moral and the institutional or the professional, that should be mentioned here. As accountability is thought to relate to obligations, to what we ought to do, it is only natural to depict the distinction between the institutional form of accountability and the moral form by appealing to two different kinds of oughts - what I take to be the professional or organizational versus what is known to be the moral. I use 'organizational' in accordance with the common organizational reference to codes of ethics, which include their specified oughts. Hence, professional or organizational duties are recognized as such mainly because they are conditioned by the identity of the agent, while moral duties are unconditioned duties. This means that one is to obey one's professional duty of medical ethics only if one is a doctor of medicine. Medical, journalistic, or any other professional duties are valid only for doctors, journalists, or any other professionals. These special duties constitute their professions and they do not impose an obligation on anyone other than the professionals concerned. This is also applicable to organizations that have many rules according to which their employees should operate. In contrast, moral duties are general and not conditioned by anybody's professional, institutional, religious, national, or any other form of identity - or by human desire or comfort. Such is the moral duty to love thy neighbour. The distinction between moral and organizational duties will 
be of help later on in this article, as social commitments and duties are thought to be derived from moral ones, rather than from any institutional commitment. Hence, two kinds of ought go along with two kinds of accountability and answerability: institutional (conditioned duties) as well as unconditioned. Consequently, two types of accountability and answerability lead to two types of responsibility. A detailed discussion on the differences between the two types of accountability will be offered later in the article. At this point I wish to examine the way in which accountability is maintained between firms and stakeholders.

\section{Corporate Social Responsibility}

Global Reporting Initiative (GRI) reports, for example, are one way for corporations to engage in deliberative democracy. The reports are used as communication tools with other stakeholders and to enhance the degree of transparency of corporations' actions. The reports have been adopted by many corporations since their launch back in 1997. Nevertheless, those who were among the first to report on environmental issues, for instance, were oil companies. It has been suggested that the reason for doing this was the pressure those corporations felt from stakeholders. In doing so, they reacted to the pressure and labelled themselves environment trustees (Fernandez-Feijoo et al. 2014).

I suggest that the use of GRI reports falls into the domain of accountability, since they are produced in response to public expectation and demand. When a corporation reports openly about its ethical, societal, and business standards, it exercises its responsibility/accountability to the public. By issuing GRI reports in the course of CSR actions, a corporation is communicating to the full-spectrum of its stakeholders the extent to which their rights and interests are being taken care of. By reporting in this way, a corporation accepts that it does not act in a void; that it is just one part of society that in turn enables a rich cultural environment for all - a bedrock for all human entrepreneurs - even the business entrepreneur. This background functions as a nursery for language, political institutions, religion, and many others that sustain and constitute human society. These are the society's foundations and they have logical and normative primacy over the corporations they support. It could be argued that fundamental components of society cannot be distinguished from organized human endeavours, as society is no more than an organized and collective mode of human existence. However, an elaborated response to such a view will be further discussed in section 4 along this article. Moreover, business enterprises are driven for the benefit, happiness, and potential self-realization of their owners, but this does not give them the permission to harm anyone in any way. As corporations function in society, they benefit from societal infrastructure in terms of qualified employees, civil security and safety, and transport- and business-based courses, and as such they are expected to return to society a share of their profits. This warrants the taxation of corporations in favour of society. But taxation does not exhaust the corporation's obligations to society as the payment of taxes does not allow corporations to conceal from the public crucial information regarding its health and safety record, for instance. This expectation to refrain from harming, when considered from political and marketing perspectives, entails corporations' transparency. Followed by the consolidation of requirements from the public side, transparency seems to increase the level of assurance that corporations will not conceal 'dirty secrets' from the public. Corporations present transparency as terms of good faith on their part, and as such, corporational transparency has become a hallmark of its moral conviction. Corporations' reports to society about their business plans and endeavours, as well as about their business performance, reflect not only moral conviction but respect for other stakeholders as well. 
After all, CSR is more inclusive than mere transparency and cannot be reduced to it or in refraining from harm alone. On a slogan level CSR aims at the same target as the traditional entrepreneur - at the improvement of societal wellbeing. The differences between the two are to be found in the details. One of the main differences between them concerns their direct contribution to society. While a large part of traditional business ethos is concentrated mainly with the contribution of firms to employment rates, CSR ethos manifests a broader sense of societal commitment such as the development of recycling industries, urban farming, veggie agriculture, environmental safety, safeguarding the rights of workers, proliferation of CSR reports, and many others. Hence, CSR is not only about refraining from harm but about active and direct steps, and the obligations that corporations should have in favour of society too.

Among this entire arsenal of duties some negative moral ones focus on refraining from doing wrong, while positive duties relate to real actions that are morally required to be carried out. Note that negative moral demands can be formulated positively as well. Refraining from theft can be formulated through the demand to respect other's property, for example, and the demand to secure fresh and clean water can be negatively put by demanding one 'not to discharge chemical waste into the soil'. Consequently, the demand from business corporations to be transparent is equivalent to the demand not to conceal its wrongdoings from those who are affected by them, namely its full-range stakeholders. Either negatively or positively those are instances of ought. Failing to comply with such CSR requirements in part or whole, makes those corporations accountable and answerable to the public for this and in many of cases corporations are liable to sanctions imposed by consumers, politicians, and the courts.

\section{Authority}

My interest in authority is confined to the boundaries of business firms and the like too. Tough authority and power may not be considered distinct by some scholars - I rather consider institutional authority to be a particular instance of power; it is a formal power as exercised by managers in organizations. By this I do not offer a definition of authority; rather I want to point to one of the major contexts in which we use the term 'authority' - in the context of organizations and politics. This is to suggest that differences in the use of power implies different human environments. Hence, a line may be drawn between organizations and society, as power is used within them in two different ways. I find Marmor's (2011) interpretation of H.L.A. Hart's ideas on the differences between the social and institutional (organizational) insightful here. First, organizations consist of secondary rules. These are the rules for using rules. Secondary rules determine which organizational agents (high-rank managers) can change the rules (primary rules) and which of them can be changed or endorsed. A primary rule may determine the authority of a CEO over employees, while a secondary one may determine how this authority is to be taken from the CEO in case of impeachment, for instance. Such formal instruments of change do not exist in society. Second, according to this view, organizations are developing tools for investigating and watching over employees' compliance and are concerned with how to respond to non-compliance. Outside the organizational realm, social pressure is replacing formal sanctions for non-compliance as well as hostile reaction. These tend to be of an informal type. The distinction may be rejected as blurring the edges. Nevertheless, it is helpful in that it fleshes out the difference in nuances. I suggest reading it in the following way: the use of power within organizations is meant to be formal, i.e. validated 
by the structure of the chain of hierarchies, while social power is mainly informal and its points of concentration are rarely as stable and defined as institutional authority is.

'Authority' in its formal appearance is of interest to law and management scholars as well as to those who practice in those areas, while 'power' is a more political, economical and social concept. Arguably, organizations are frequently described as consisting of a chain of hierarchies that distinguishes between managers, who issue directives, and employees, who follow them. Being able to operate collectively according to management decisions and directives is what makes them eligible to bear responsibility for their actions as an organization (French 1984; Pettit 2007). Consequentially, a manager in a corporation is said to have authority over an employee in virtue of some organizational formal definitions of one's role, which determines the latter as subject to the former. Among other things, being a subject to the manager means that one is expected to carry out the manager's directives.

The question of the sources of authority in general and in organizations in particular had been discussed by many with little agreement (Raz 1986; Osorio-Kupferblum 2015; van Oosterhout 2007; Marmor 2011; McMahon 1994). I will not engage in this discussion here, as it will lead us astray from my purposes, which is to investigate the accountability relations between those who issue directives and those who carry them out.

\section{Authority and Accountability}

I borrow Marmor's phrase - 'Accountability relations' - to refer to the normative aspect of authority-subject relations within corporations (business like and other types of organizations as well) (Marmor 2011). In organizations, managers hold legitimate authority over their teams and employees. Institutional authority defines its possessors as managers. The organization's structure and norms render definite reciprocal responsibilities between employees and managers. Employees conform to a contract. Furthermore, as an employee one enters voluntarily into a network of institutionally acknowledged authorities. This bond between the parties is authority-subject relations that entail the subject being accountable and answerable to the manager.

One aspect of such accountability is negative, i.e. it refers to a disobedient subject. Failing to conform to managerial directives renders one accountable for this. This only underscores the deontic nature of accountability that Macnamara assumes, though now in an institutional context. Negative cases of accountability, i.e. cases in which an employee fails to follow managerial directives, often invoke negative reactions, demands for good excuses (answerability), and, in some cases, even sanctions on the employee.

I assume that negative cases of accountability are quite common and familiar. Nevertheless, they do not exhaust all its aspects, nor are they suitable for in-depth understanding of such relations. Instead, I turn now to the positive face of accountability, where, I believe, there is more to learn. Consider a manager in a firm that issues a directive to one of her employees to contact all the firm's late paying customers and to collect their payments. The employee, being in accountability relations with the manager, has to:

1. Report the number of late payers she reached, how many of them paid their debt, and if it was paid in full.

2. If a problem arises in the process of collecting the debts, notify the manager so she can pursue some other way of completing the job.

3. Being answerable, the employee has to be able to explain and justify her approach to the manager, as well as the subsequent actions she takes in order to accomplish the directive. 
Two things can be concluded from this: First, being responsible in this way consists of three second-order duties (except that of completing the original task of collecting the customers' debts). Second, accountability relations relate mostly to positive duties i.e. to reporting, justifying the mode of operation (answerability), and to informing the manager if a problem occurs.

Accountability relations in organizations reflect a hierarchical mode of collective operation. Normally, managers and employees strive in combined efforts to reach their organizational goals. The nature of such undertakings is to be understood as opposed to the family environment. Family relations are based on emotional attitudes toward other family members, while in organizations personal relations are often restricted to a minimum, which are not to threaten the formal categories and divisions of authority. It could be argued that this is an unjustified generalization, as in some organizations emotional and personal relationships are being formed and maintained. Medical staff in hospitals as well as worriers' teams in the army could be considered as counter-examples to my account. However, my argument doesn't propose a dichotomy between family and institutions, but rather separation on a continuum, and it is made to especially fit business corporations. Furthermore, even in such examples, team intimacy doesn't cast a shadow over the whole net of formal organizational engagements and hierarchies. These intimacies are maintained in small teams rather than in large scale units. Eva Illouz (Illouz 2007) claims that in spite of the emotionality which permeates organizational life in the west, it is of a reduced intensity, which enables us to control emotions rather than being controlled by it.

Emotional relations motivate family members to enrich and protect their togetherness as a mutual interest. Such a goal is set implicitly by responding to basic human needs such as love, comfort, and raising children. By a way of contrast, those emotional motives are scarce in the sphere of organizations, especially in business corporations. Employees of all ranks combine their efforts to reach goals that are far beyond their collective emotional well-being. In the organizational sphere, friendship, compassion, empathy, and individual empowerment are perceived as a means to some other goal, not as goals in themselves. Business organizations rarely make full organic communities. The latter is distinguished from them by the nature of their inner goals (MacIntyre 1984). In contrast, business corporations are rather engineered as tools with the purpose of achieving pre-determined goals that are not reachable by individuals alone. Their founders set their goals and invite others to contribute their abilities, as employees, to already-set objectives on the founders' terms. Those who respond to the corporation's call and become its employees can expect economic rewards as a condition for their work. Their relations with the managers and with other employees are constituted by contractual agreements that determine the economic rewards vis-a-vis their level of professional contribution to the corporations.

The contractual relations within a corporation determine the reciprocal core commitments between the corporation and the employee. It is a matter of mutual giving and receiving. An employee is expected to give to the corporation and consequently to be rewarded by it. It is granted that giving and receiving are not the same. On the one hand an employee is paid and on the other hand he or she contributes to the corporation by investing his or her time and practical knowledge. By way of comparison, in the family, giving in many ways means receiving.

To recap, normally employees work for corporations, according to the latter's rules and goals. Furthermore, employee relations with their managers and colleagues are determined by formal contracts that place them in a network of authority. To conclude, in a corporational environment, emotions as motivation to act seem to be radically boiled-down. Formal and 
explicit authority alongside expectations for income take the place of emotion as a motive for action, the role it plays in family life. Appropriate responses to authority are then defined by means of organizational ethics in such a way as to avoid arbitrary or emotional actions. Due to their accountability relations, managers and employees can consolidate their forces to advance corporate goals. So perceived, enhancing collective interests works differently in the corporational context than in a small community or family one.

\section{Accountability vs. Authority and Power}

Authority and power are not the same. They are two separate modes of exercising influence: one within organizations and the other out of organizations. Nevertheless, both are connected to accountability in distinct ways; therefore, they are involved in constituting two concepts of responsibility. Accountability relations within institutions are of an organizational kind, while outer-organizational accountability relations are of a social kind.

The organizational concept of accountability is confined within the boundaries of the organization. That is to say, once a person ceases to be an employee, i.e. the person becomes separated from the corporation, most of the accountability relations he or she had to his or her former managers expire altogether. At the same time, a separation of the corporation and the civil society in which it operates is possible only through the corporation's dissolving. Hence, unless a corporation ceases to exist, it is still bound to its obligation to report to the public about its performance and to avoid harm. Furthermore, a corporation existing in the absence of social society seems more like a science-fiction scenario. Through this, another level of connection between civil society and the market is revealed. According to this idea, the existence of society is more deeply rooted than corporations, and hence society needs and rights possess moral primacy over the inner-organizational form of accountability.

Sometimes, rival kinds of accountability clash. Consider the tension between organizational accountability and social accountability. Cases of whistle-blowing, for example, are cases in which an employee faces two opposing accountabilities-relations: one that relates to the ethical demand to proceed with his or her directives, in contrast with the social demand to inform society about wrongdoings against the public on the part of the corporation. It is interesting to note that if an employee blows the whistle and informs the public about wrongdoings perpetrated by the corporation, this, of course, will not be considered as qualifying for the corporation's CSR standards, since it was not the corporation that formally decided to report to the public, although the source of information falls within its boundaries. Lack of authority disqualifies this report as fulfilling the corporation's own accountability - to society. The whistle-blower does not possess any institutional authority to report to the public about the corporation's conduct. Such a case fleshes out that a necessary condition for an employee to act in the name of the corporation is to possess the institutional authority to do so. This illuminates an important point. In CSR cases, authority and CSR are intertwined as authorized action precedes and conditions CSR. Initiating CSR operations depends on the existence of institutional authority, which issues suitable directives for social interventions. In brief, CSR endeavours depend on authorized decisions.

Exercising CSR accountability differs from acting according to the organizational form of accountability. At the organizational level, accountability requires the execution of three positive duties (justification of one's action and two kinds of report) beyond the direct one. On the CSR level, reports are issued as a result of a deliberative social process. In contrast to an 
employee, a corporation is not compelled by any formal reasons to issue a (GRI) report. This depends upon the corporation's goodwill and its deliberative surroundings. This difference is related to H.L.A. Hart's above-mentioned distinction between the social realm and the institutional one. Societal demands and sanctions tend to be informal, and as such they are hardly uniform.

While organizational accountability relates to three supplementary duties of explaining and reporting apart from the main directive, CSR includes only two of these additional duties, namely, to contribute to societal well-being and to report about it (that is, issue GRI reports). Being more accurate, this sole report (the CSR report) does not relate directly to the success or failure of the corporations' business-driven actions, while organizational accountability consists in a tightened connection to the employee's liability, i.e. the employee's first-order directive. I see two differences between the two cases of accountability here. First, the CSR report is not addressed to the corporation's managers or its owners, but rather to the public, while the employee reports directly to his or her manger. Second, these reports are addressed to different parties (the public vs. the manager), according to different requirements, and contain different kinds of information. The CSR report relates to the public interest, which is (almost) altogether different from that of its owners and managers, who mostly focus on the corporations' success in terms of financial results.

Business corporations are not charitable institutions. They are constituted by a will to increase profits and as such they are not defined by their efforts to support and empower the underprivileged in society. Business purposes are different from moral and societal obligations. Making an economic profit is voluntary, while moral or societal obligations are not. Corporations report about their business performance if they are public corporations whose stocks are traded on the stock market. Nevertheless, in case of private firms, i.e. those that do not share or trade their stocks in the market, business performance is usually kept under a veil of ignorance from the public and from their employees as well. It is worth noting that CSR operations can be described as negative as well as positive duties. There is a difference between avoiding using toxic materials in the manufacturing process of an appliance on the one hand, and the adopting of an orphanage by the corporation on the other hand. The first is known as a negative moral duty, while the second is a social commitment that manifests corporations' commitments to do something rather than taking an attitude of avoidance. Consequentially, a GRI report includes both positive commitments and negative ones. By contrast, ethical accountability often relates to positive duties, since the nature of managerial directives is positive and relates to actions towards some specific ends. The latter difference may be approached from another perspective, which would sharpen it. Inner-organizational accountability means that one (or more than one employee, even a team) is accountable and answerable to a manager for executing a directive. In most cases, managerial directives within corporations refer to actions that are required for the continuous operation of the corporation as a whole. A distinction between carrying out the manager's directive (first-order duty) and the duties that hinge on the expected reports (second-order duties) should be maintained here. Employees bear responsibility to their managers for their institutional tasks on behalf of the entire organization, i.e., they are responsible to $Y$ for $X$. On the other hand, at the CSR level of accountability, reporting and implementing responsibility is linked to the same beneficiary. At the CSR level, there are not two distinct kinds of duties (first and second order duties), but only one kind: corporations' responsibility to their stakeholders to be supportive and protective of them. Therefore, at the CSR level responsibility to X is at the same time responsibility for X. In this sense, reporting is equivalent to any other social undertaking on the part of a corporation. 
Those considerations reflect on answerability as well. Being answerable to a manager means that an employee has to justify the measures taken while completing routine organizational tasks. Many inner institutional reports include explanations alongside the reported facts. Routine debriefing of teams is a familiar practice in which such explanations are expected of attendees. Such explanations are best understood as institutional practices aimed at increasing the professionalism and the efficiency of teams - as part of the institutional training programs. As such they have little connection to cases of blameworthiness. By contrast, CSR answerability relates to cases of blameworthiness on the corporation's part. The latest Volkswagen scandal concerning the corporation's conspiracy to conceal their rates of polluted emissions is an example of answerability of this kind. The Volkswagen senior management could not vanish in silence. They had to answer to the public for their conduct.

Another difference between CSR accountability and organizational accountability relates to another aspect of voluntarism. A substantial corporational GRI report may refer to many of its social commitments. Since these are commitments and not duties or moral obligations, they are selected more or less voluntarily by the corporation. By contrast, at the organizational accountability level the reports are not voluntary in nature. They are shaped by professional and institutional rules.

While in an organization the authority relations stand between managers and their subjects, at the CSR level the relations are between a whole corporation and a variety of its stakeholders. The latter has an effect on how conflicting cases of accountability can be balanced. Consider a case in which the more a corporation invests in its social endeavours the less profits are generated. This may raise the problem of conflicting loyalties on the part of the CEO. That is, whether the CEO should operate according to stockholders' standards or that of other stakeholders. At the organizational accountability level, such a problem, if it arises, can be sorted out by appealing to a higher source of authority, which seems to be dissolved and absent in the CSR context.

\section{Conclusion}

To conclude, exposing the differences between CSR accountability and inner-organizational accountability reveals two distinct types of accountability, which in turn entails two distinct concepts of responsibility. Reporting and refraining from doing harm are their common denominators, while other properties distinguish between them.

Organizational accountability is exercised with a link to organizational authority, while CSR accountability is implemented vis a vis outer institutional surroundings i.e. society and its representatives. The different nature of the relations between corporations and society and between employees and managers rests in the distinction between the two kinds of accountability. Since accountability and answerability are components of organizational responsibility, (alongside liability and imputability), introducing changes in accountability transforms the perception of responsibility as well. Organizational accountability is related to three second-order positive duties of reporting and explaining in addition to the original first-order directive, while CSR kind of accountability is related to two duties, namely to advance societal and civil wellbeing and to report about its actions. This very report should refer to how well the corporation fulfils its responsibility to the public for the public. In other words, the liability component and the accountability of the CSR converge at this point. 
Both of these responsibilities are implemented in accordance with others, but in different contexts and in different ways. Compared to organizational responsibility, the nature of CSR is looser and thus shaped through constant friction with societal forces. These differences seem to reflect an important feature of collective human labour: its ambition for achievement, which allows little room for unsynchronized work.

Though comparing these three strings of accountability enriches our understanding of responsibility, there is more work to be done. Elaborating on what kinds of reactions to CSR and institutional accountability (emotional? formal? political?) are appropriate for holding organizations accountable is one vein of further investigation. Another would be to develop a theory that connects several types of authority to their respective types of accountability.

\section{Compliance with Ethical Standards}

Conflict of Interest On my behalf, I as a corresponding author state that there is no conflict of interest.

\section{References}

Alchian, Armen A., and Harold Demsetz. 1972. Production, information costs, and economic organization. American Economic Review 62: 777-795.

Anderson, Elizabeth. 1990. The ethical limitations of the Merket. Economics and Philosophy 6 (2): 179-205.

Arenas, Daniel, Pablo Sanchez, and Matthew Murphy. 2013. Different paths to collaboration between businesses and civil society and the role third Perties. Journal of Business Ethics 115: 723-739.

Burchell, Jon, and Joanne Cook. 2013. Sleeping with the enemy? Strategic transformations in business-NGO relationships trough stakeholder dialogue. Journal of Business Ethics 113: 505-518.

Carrington, Damian. 2015. The Guardian. Former foes Greenpeace and Enel stand together in low-carbon push. https://www.theguardian.com/environment/2015/oct/22/former-foes-greenpeace-and-energygiant-enelstand-together-in-low-carbon-push. Accessed 3 June 2017.

Detomasi, David Antony. 2008. The political roots of corporate social responsibility. Journal of Business Ethics 82: $807-819$.

Dreier Peter. 1999. The campus anti-sweatshop movement. The American Prospect. http://prospect. org/article/campus-anti-sweatshop-movement. Accessed 3 June 2017.

Fernandez-Feijoo, Belen, Silvia Romero, and Silvia Ruiz. 2014. Effect of stakeholders' pressure on transparency of sustainability reports within the GRI framework. Journal of Business Ethics 122: 53-63.

French, Peter. 1984. Collective and corporate responsibility. New York: Columbia University Press.

Habermas, Jurgen. 1998. Between facts and norms. MA: MIT Press.

Habermas, Jurgen. 2001. The Postnational constellation. Cambridge: MIT Press.

Illouz, Eva. 2007. Cold intimacies: The making of emotional capitalism. London: Polity Press.

Lee, Hsin-Hsuan Meg, Willemijn Van Dolen, and Ans Kolk. 2013. On the role of social media in the 'Responsible' food business: Blogger buzz on health and obesity issues. Journal of Business Ethics 118: 695-707.

MacIntyre, Alasdair. 1984. After Virute: A study in moral theory. Notre Dame: University of Notre Dame Press.

Macnamara, Coleen. 2011. Holding others responsible. Philosophical Studies 152: 81-102.

Marmor, Andrei. 2011. An Insitiutional conception of authority. Philosophy \& Public Affairs 39: 238-261.

McKenny, Gerald P. 2005. Responsibility. In Theological Ethics, ed. Gilbert Meilaender and William Werpehowski. Oxford: Oxford University Press.

McMahon, Christopher. 1994. Authority and democracy: A general theory of government and management. Princeton: Princeton University Press.

Osorio-Kupferblum, C. Naomi. 2015. Conceptualising "authority". International Journal of Philosophical Studies 23 (2): 223-236.

Pellizzoni, Luigi. 1999. Reflexive modernization and beyond: Knowledge and value in the politics of environment and technology. Theory, Culture and Society 16 (4): 99-125.

Pettit, Philip. 2007. Responsibility incorporated. Ethics 117: 171-201. 
Pies, Ingo, Markus Beckmann, and Stefan Hielscher. 2014. The political role of the business firm: An Ordonomic concept of corporate citizenship developed in comparison with the Aristotelian idea of individual citizenship. Buisness \& Society 53 (2): 226-259.

Pink, Thomas. 2009. Power and moral responsibility. Philosophical Explorations 12 (2): 127-149.

Raz, Joseph. 1986. The morality of freedom. Oxford: Clarendon Press.

Robinson, Simon. 2009. The nature of responsibility in a professional setting. Journal of Business Ethics 88: 1119. doi:10.1007/s10551-009-0103-3.

Scherer, Andreas Georg, and Guido Palazzo. 2004. Toward a political conception of corporate responsiblity: Business and society seen from a Habermasian perspective. Academy of Management Review 32 (4): 10961120 .

Scherer, Andreas Georg, Guido Palazzo, and Dirk Matten. 2014. The Buisness firm as a political ACtor: A new theory of the firm for a globalized world. Buisness \& Society 53 (2): 143-156.

Schrempf, Judith. 2014. A social connection approach to corporate responsibility: The case of the fast-food industry and obesity. Business \& Society 53 (2): 300-332.

Shoemaker, David. 2011. Attributability, answerability, and accountability: Toward a wider theory of moral responsibility. Ethics 121: 602-632.

Siltoja, Marjo E., and Tiina J. Onkila. 2013. Business in society or business and society: The construction of business-society relations in responsibility reports from a critical discursive perspective. Business Ethics: A European Review 22 (4): 357-373.

Strawson, Peter. 1993. Freedom and resentment in Perspectives on Moral Responsibility. In, ed. J.M. Fischer and M. Ravizza, 45-66. Ithaca: Cornell University Press.

van Oosterhout, J. (Hans). 2007. Authority and democracy in corporate governance? Journal of Business Ethics 71: $359-370$.

Watson, Gary. 2009. Two faces of responsibility. In Agency and answerability, 260-288. New York: Clarendon Press Oxford.

Xu, Kaibin, and Wenqing Li. 2012. An ethical stakeholder approach to crisis communication: A case study of Foxconn's 2010 employee suicide crisis. Journal of Business Ethics 117 (2): 371-386.

Robert Albin is an Assistant Professor of Philosophy and the former Chair of the Department of Liberal Arts at Sapir College, Israel. His Research interests are in the field of ethics (both general and applied ethics) with a special interest in business and organizational ethics. He is a Member of the Committee for Living organ Transplants, at The Soroka Medical Center, Beer-Shave. Israel. 